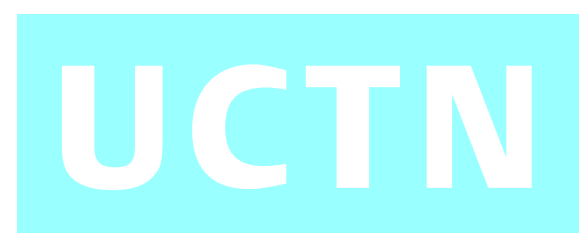

\title{
Esophageal Intramural Pseudodiverticulosis with Symptomatic Stricture: Mediastinitis and Papillomatosis as a Complication of Endoscopic Intervention
}

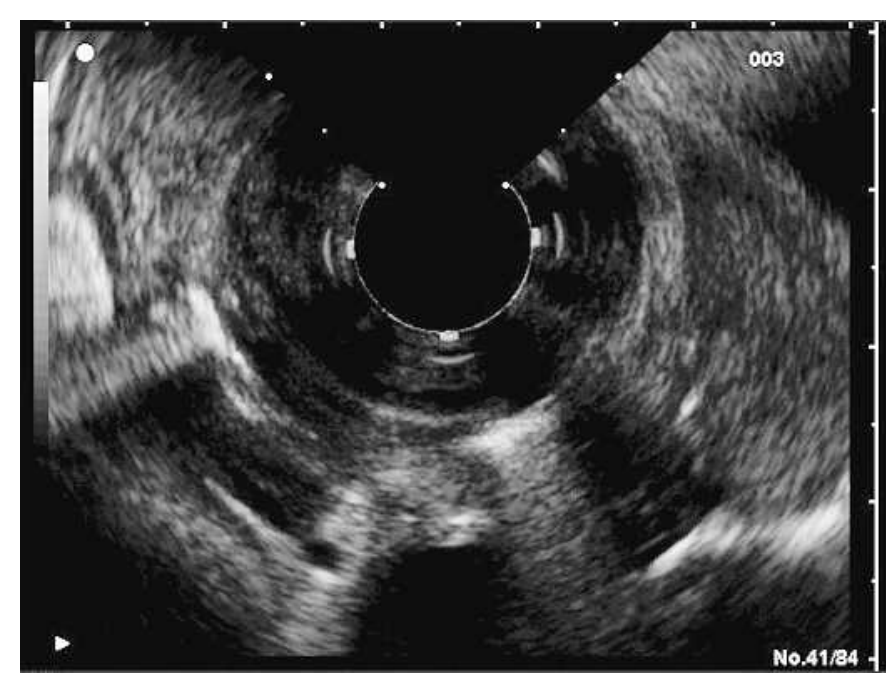

Figure 1 Radial endoscopic ultrasound image showing a thickened esophageal mucosa and submucosa with a normal muscularis propria. Air can be seen outside the esophageal wall, in the mediastinum, at the 5 o'clock and 8 o'clock positions.
Patients with esophageal intramural pseudodiverticulosis (EIP) usually develop symptoms because of complications such as gastroesophageal reflux, motility disorders, infections, strictures, fistulas, bleeding, or perforation.

A 44-year-old man with EIP developed an inflammatory stricture of the distal esophagus. The stricture was dilated on three occasions, up to $51 \mathrm{Fr}$, but the effect was short-lived, so we decided to insert a covered Polyflex stent ( $12 \mathrm{~cm}, 25 / 22 \mathrm{~mm}$ ). This therapy was successful and the stricture was found to have disappeared when the stent was removed 1 month later. However, the stent induced a perforation of a diverticulum beneath the former covering, which we demonstrated on endoscopic ultrasound, which showed an echo-poor area of thickening of the esophageal mucosa and submucosa with a normal muscularis propria [1] and air in the mediastinum (Figure $\mathbf{1}$ ). The mediastinitis was treated conservatively. Stroma-rich papillomas were resected from what had been the distal margin of the stent (Figure 2 ). The patient has been asymptomatic during 1 year of follow-up and the endoscopic ultrasound appearance has not changed.
This is the first description of a mediastinitis induced by an endoscopic intervention in EIP. Four cases of spontaneous rupture of a pseudodiverticulum with periesophageal abscess or mediastinitis have been described [2-5]. In EIP with recurrent dysphagia caused by persistant stricture the choices for management are forced endoscopic treatment or surgery. Temporary stent insertion is one possible way of relieving the dysphagia. The covered Polyflex stent has great potential in the treatment of strictures, but the use of a covered stent can lead to the serious complication of mediastinitis. The use of an uncovered metal stent, on the other hand, can lead to earlier tissue overgrowth through the mesh, and removal of the embedded metal stent will be technically difficult.

\section{Competing interests: None}

Endoscopy_UCTN_Code_CCL_1AB_2AC_3AF Endoscopy_UCTN_Code_CPL_1AH_2AF

\section{Brenke, I. Wanzar, U. Will}

Department of Internal Medicine III, City Hospital, Gera, Germany.

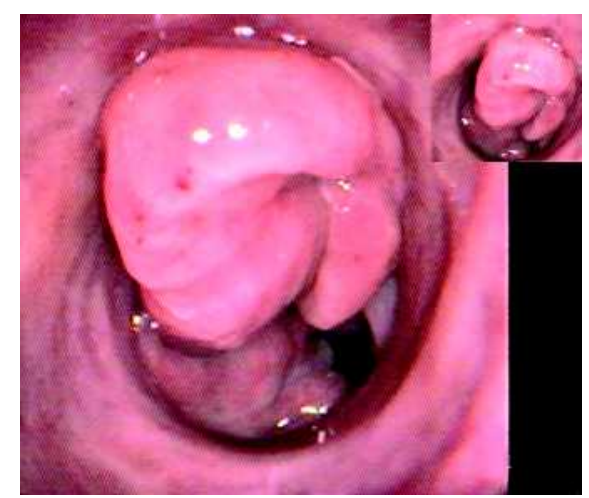

Figure 2 Esophagogastroduodenoscopy after removing the Polyflex stent showed lumen-narrowing papillomas at the former site of the distal stent margin, in the lower third of the esophagus.

\section{References}

${ }^{1}$ Devereaux CE, Savides TJ. EUS appearance of esophageal pseudodiverticulosis. Gastrointest Endosc 2000; 51: 228-231

${ }^{2}$ Wong J, Walton M, Issenman R. Ruptured esophageal intramural pseudodiverticulum: an unusual cause of mediastinitis in a child. Can J Surg 1999; 42: 389-391

${ }^{3}$ Abrams LJ, Levine MS, Laufer I. Esophageal peridiverticulitis: an unusual complication of esophageal intramural pseudodiverticulosis. Eur J Radiol 1995; 19: 139-141

${ }^{4}$ Kim S, Choi C, Groskin SA. Esophageal intramural pseudodiverticulitis. Radiology 1989; 173: 418

${ }^{5}$ Rahlf G, Wilbert L, Lankisch PG, Huttemann U. Intramural esophageal diverticulosis. Acta Hepatogastroenterol 1977; 24: $110-$ 115

\section{Corresponding Author}

\section{U. Will, M.D.}

Department of Internal Medicine III City Hospital

Strasse des Friedens 122

07548 Gera

Germany

Fax: $\quad+49-365-828-2402$

E-mail: uwe.will@wkg.srh.de 